\title{
Hospital-acquired complications in critically ill patients
}

\author{
Graeme J Duke, Frank Shann, Cameron I Knott, Felix Oberender, David V Pilcher, Owen Roodenburg
} and John D Santamaria

Every disease, intervention and drug carries an inherent risk of complications. Some complications are unavoidable, but it is important to know when they exceed a minimum level. The Classification of Hospital Acquired Diagnoses ${ }^{1-3}$ (CHADx) and the national hospital-acquired complications $(\mathrm{HAC})^{2,4}$ program were developed for this purpose.

CHADx groups 4500 separate diagnoses into a hierarchy of 17 classes and 145 subclasses. ${ }^{1}$ The Australian Commission on Safety and Quality in Health Care has endorsed a subset of high impact $\mathrm{HAC}^{2}$ with 15 classes and 38 subclasses, for the purpose of monitoring and reporting hospital complication rates. Reported hospital rates of CHADx and HAC events range from $10-15 \%$ to $2-3 \%$ respectively. ${ }^{2-4}$ Both are derived from administrative data ${ }^{3}$ collated independently of the staff they monitor and have relevance to all health services and clinical specialties.

The purpose of CHADx and HAC is to "characterise hospital-acquired conditions" and "allow hospitals to track monthly performance for any of [these] indicators, or to evaluate specific quality improvement projects". ${ }^{1}$ In this paradigm, complications are defined as diagnoses that are not present on admission but arise after a patient is hospitalised; require additional treatment, monitoring or an extended length of stay; and may be mitigated by clinical intervention. ${ }^{2}$ Variation in HAC rates between similar health services (or clinical departments) is assumed to indicate a variation in the standard of care. ${ }^{2,4}$

This definition of hospital complications encompasses two distinct subgroups ${ }^{5}$ (Table 1): health care-related complications (errors) and patient-related complications arising from pre-admission comorbidities or side effects of optimal treatment.

Examples of health care-related errors include atrial fibrillation from inadvertent cessation of antiarrhythmic therapy or inadequate analgesia and thromboembolism in the absence of any prophylaxis. Patient-related complications include rapid atrial fibrillation complicating cardiac surgery, sepsis, or thrombocytopenia complicating heparin therapy. Clinicians delivering high quality care will

\section{ABSTRACT}

Background: The national hospital-acquired complications (HAC) system has been promoted as a method to identify health care errors that may be mitigated by clinical interventions.

Objectives: To quantify the rate of HAC in multiday stay adults admitted to major hospitals.

Design: Retrospective observational analysis of 5-year (July 2014 - June 2019) administrative dataset abstracted from medical records.

Setting: All 47 hospitals with on-site intensive care units (ICUs) in the State of Victoria.

Participants: All adults (aged $\geq 18$ years) stratified into planned or unplanned, surgical or medical, ICU or other ward, and by hospital peer group (tertiary referral, metropolitan, regional).

Main outcome measures: HAC rates in ICU compared with ward, and mixed-effects regression estimates of the association between HAC and i) risk of clinical deterioration, and ii) admission hospital site (intraclass correlation coefficient $[\mathrm{ICC}]>0.3)$.

Results: 211120 adult ICU separations with mean hospital mortality of $7.3 \%(95 \% \mathrm{Cl}, 7.2-7.4 \%)$ reported 110132 (42.6\%) HAC events (commonly, delirium, infection, arrhythmia and respiratory failure) in 62945 records (29.8\%). Higher HAC rates were reported in elective (cardiac [50.3\%] and non-cardiac [40.6\%]) surgical subgroups compared with emergency medical subgroup $(23.9 \%)$, and in tertiary (35.4\%) compared with non-tertiary (22.7\%) hospitals. HAC was strongly associated with on-admission patient characteristics $(P<0.001)$, but was weakly associated with hospital site (ICC, $0.08 ; 95 \% \mathrm{Cl}, 0.05-0.11$ ).

Conclusions: Critically ill patients have a high burden of HAC events, which appear to be associated with patient admission characteristics. HAC may an indicator of hospital admission complexity rather than hospital-acquired complications.

Crit Care Resusc 2021; 23 (3): 285-91 


\section{ORIGINAL ARTICLE}

\begin{tabular}{|c|c|c|}
\hline HAC classification & Health care-related & Patient-related \\
\hline Description & $\begin{array}{l}\text { Health care error with } \\
\text { suboptimal care }\end{array}$ & $\begin{array}{l}\text { Complication of disease or } \\
\text { treatment with optimal care }\end{array}$ \\
\hline Effect on length of stay & $\uparrow$ & $\uparrow$ \\
\hline Effect on mortality risk & $\uparrow$ & $\uparrow$ \\
\hline Effect on health care cost & $\uparrow$ & $\uparrow$ \\
\hline Predictable & No & Yes \\
\hline Influenced by standard of care & Yes & No \\
\hline Indicator of & Safety and quality & Patient complexity \\
\hline Higher rate indicative of & Suboptimal care & Sicker patients \\
\hline Method of identification & $\begin{array}{l}\text { - Clinical audit/review } \\
\text { - Adverse event reports }\end{array}$ & $\begin{array}{l}\text { - Clinical audit/review, } \\
\text { - HAC classification system }\end{array}$ \\
\hline Interventions to reduce rate & $\begin{array}{l}\text { - Training } \\
\text { - Education } \\
\text { - Resources }\end{array}$ & $\begin{array}{l}\text { - Informed consent } \\
\text { - Patient selection } \\
\text { - Clinical research }\end{array}$ \\
\hline
\end{tabular}

reconstruct a chronological sequence or impute causation.

All adult (age $\geq 18$ years) multiday separations were included. Paediatric, palliative care, mental health, and daycase procedures were excluded. Records were dichotomised into patients admitted to the ICU and those who were not (ward subgroup). Data available for each record included patient demographic characteristics (age, sex, emergent status), source of admission (home, hospital transfer, aged-care facility), admission diagnoses, year of hospital separation, major procedures and interventions, and hospital outcomes (length of stay and

seek to reduce health care-related complications and identify (and treat) all patient-related complications. CHADx and HAC definitions capture both complication types but cannot distinguish them. ${ }^{2,3}$

Patients likely to benefit from monitoring and treatment of complications are those at greatest risk, ${ }^{1,2}$ such as patients admitted to an intensive care unit (ICU). The rates of CHADx and HAC events in critically ill patients are unknown. We sought to quantify the rate of HAC events in patients admitted to the ICU compared with those who were not, and estimate the influence of patient-related and hospital-related factors.

\section{Methods}

The State of Victoria, Australia, has a population of 6.4 million and 50000 adult ICU separations per annum. This report covers the 5-year period from 1 July 2014 to 30 June 2019.

Data were abstracted from medical records at the time of hospital separation to inform the Victorian Admitted Episode Dataset $(\mathrm{VAED})^{6}$ for the purposes of epidemiology and funding. Each record includes patient demographic characteristics and outcomes with a maximum of 40 International Classification of Diseases, tenth revision, Australian modification (ICD-10-AM) ${ }^{7}$ diagnoses codes and 40 Australian Classification of Health Interventions $(\mathrm{ACHI})^{8}$ procedure codes. A "condition onset" flag 9 attached to each diagnosis distinguishes conditions present on admission from those arising after admission. Of note, the study dataset did not contain date and times to accurately final disposition). Published algorithms were employed to identify chronic health status ${ }^{10}$ and clinical frailty. ${ }^{11}$

Version $3^{12}$ of the HAC algorithm was applied to the dataset. Each record was afforded one of more HAC events (maximum 38) which were then summed for each record.

Records were stratified by admission status (emergent or planned), surgical (cardiac or non-cardiac) or medical separation, and hospital peer group - tertiary referral (providing cardiac and neurosurgical services), metropolitan (without cardiac surgical services), or regional/rural (remaining services). A major health service was defined as an acute care hospital with an onsite intensive care service.

\section{Statistical analysis}

Grouped data are reported as mean with 95\% confidence interval (CI) or median and interquartile range (IQR) where appropriate. HAC rates are also reported per 100 hospital bed-days to adjust for duration of exposure. HAC events were analysed separately for strength of association with patient admission factors, hospital site, in-hospital death, and length of stay in survivors.

The risk of clinical deterioration (in-hospital death) for each separation was obtained by fitting a two-level mixed-effect probit regression estimator, adjusted for confounding by patient demographic characteristics, admission diagnoses, admission status and source, chronic disease and frailty, and hospital length of stay, with year of admission as a random intercept. Candidate variables with $P<0.157^{13}$ were retained and the final model selection based on standard Akaike and Bayesian information criteria. ${ }^{14}$ 


\section{ORIGINAL ARTICLE}

The association between HAC and patient factors (present at the time of hospital admission) and the admitting hospital site were obtained by fitting a mixedeffect regression estimator to HAC events, incorporating the aforementioned risk of clinical deterioration (death in hospital) as a fixed effect, and hospital site as a random intercept, dichotomised by ward.

The relationship between (on-admission) risk of clinical deterioration and HAC is displayed as a plot of the marginal estimates, which provides a graphical display of this relationship while holding other covariates fixed. The relationship between hospital site and HAC was quantified by the (conditional) intraclass correlation coefficient (ICC), ${ }^{15}$ where a value of zero indicates that HAC events are independent of hospital site and a value of one indicates HAC events are solely dependent upon the admitting hospital.

The Eastern Health Human Research Ethics Committee (LNR2020-199585) approved this research. Patient and hospital sites were de-identified and the need for patient consent was waived. The analysis was performed using Stata/MP v16.1 (StataCorp, College Station, TX, USA).

\section{Results}

Over 5 years, there were 14.18 million acute care separations to 283 (public and private) health services throughout the State of Victoria, including 11.88 million $(83.8 \%)$ admitted to $47(16.6 \%)$ major health services. After exclusions (Figure 1), the study population of 2.20 million included $211120 \mathrm{ICU}$ (9.6\%) and 1.99 million ward $(90.4 \%)$ multiday stay separations.

\section{Demographic characteristics}

Demographic characteristics for the relevant subgroups are provided in Table 2 . Of note, patients in the ICU cohort

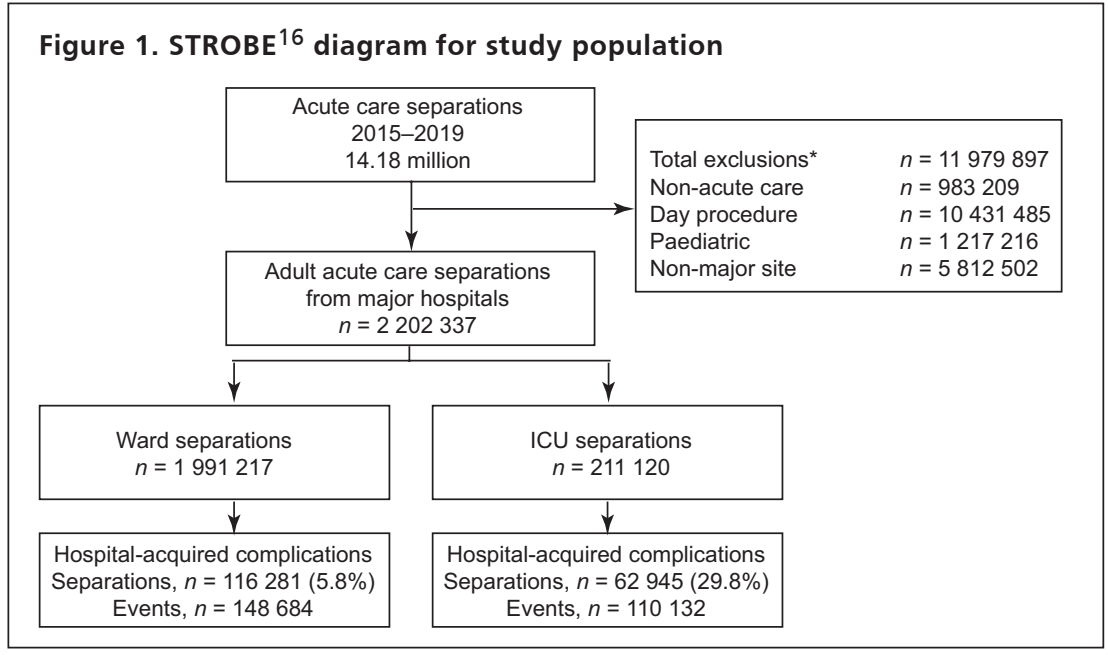

were significantly older $(P<0.001)$, experienced much longer length of stay (median, 7 days [IQR, 4-13 days] $v 4$ days [IQR, 2-6 days]) and higher (crude) mortality (mean, $7.3 \%[95 \% \mathrm{Cl}, 7.2-7.4] \vee 1.4 \%[95 \% \mathrm{Cl}, 1.4-1.5])$ than the (non-ICU) ward separations.

A total of 95528 (42.5\%) ICU separations received lifesustaining interventions, with mechanical ventilation being the most common ( $n=66682,31.6 \%)$. Major surgery was responsible for 67761 (32.2\%) ICU separations, including $26550(12.6 \%)$ cardiac surgical cases. The majority of these were planned (elective) procedures: 21163 (79.7\%) in the cardiac and 26476 (64.2\%) in the non-cardiac surgical subgroups.

\section{HAC results}

There were 62945 (29.8\%) ICU separations coded with 110132 (42.6\%) HAC events at a mean rate of 4.79 (95\% $\mathrm{Cl}, 4.76-4.82$ ) per 100 bed-days (Table 3). By comparison, there were 116281 (5.8\%) multiday stay ward separations coded with 148684 (57.4\%) HAC events at a mean rate of 1.31 (95\% Cl, 1.30-1.32) per 100 bed-days.

The most commonly reported complications were delirium (HAC \#16.1), urinary infection (\#3.1), pneumonia (\#3.3), sepsis (\#3.9), arrhythmia (\#14.2) and hypoglycaemia (\#13.2) (Table 2). These diagnoses accounted for $60 \%$ of all reported HAC events (Online Appendix). Respiratory failure (HAC \#16.1) and renal failure (\#8.1) accounted for a larger proportion of HAC events in the ICU cohort $5.4 \%$ and $1.6 \%$ respectively) compared with the ward cohort $(0.4 \%$ and $0.2 \%$ ) (Online Appendix).

All HAC subclasses were associated with a prolonged (risk-adjusted) length of stay, and most ( $n=28,84.8 \%$; $P<0.05)$ were associated with an increase in hospital mortality risk. There was a small temporal decline in the frequency of coding of HAC events (odds ratio, 0.97 per year; $95 \% \mathrm{Cl}=0.96-0.98 ; P<0.001)$ over the 5 years. Whether this represented a change in incidence, documentation or coding cannot be specified from this dataset.

\section{ICU subgroups}

Within the ICU cohort, HAC event rates were highest in patients undergoing elective cardiac surgery (mean, $6.7[95 \% \mathrm{Cl}, 6.6-$ 6.8] per 100 bed-days), invasive mechanical ventilation without cardiac surgery (mean, 6.1; $95 \% \mathrm{Cl}, 6.0-6.2)$, non-invasive ventilation support (mean, 5.1; $95 \% \mathrm{Cl}$, 5.0-5.2), and elective non-cardiac surgery (mean, 4.8; 95\% Cl, 4.7-4.9). Lower HAC rates were reported in ICU separations not 
Table 2. Demographic characteristics and rates of hospital-acquired complications (HAC) events for study subgroups

\begin{tabular}{|c|c|c|c|c|c|c|c|}
\hline Group & Ward & ICU & $\begin{array}{l}\text { Cardiac } \\
\text { surgery }\end{array}$ & $\begin{array}{c}\text { Major } \\
\text { surgery* }\end{array}$ & ICU tertiary & $\begin{array}{l}\text { ICU major } \\
\text { metropolitan }\end{array}$ & $\begin{array}{l}\text { ICU rural/ } \\
\text { regional }\end{array}$ \\
\hline $\begin{array}{l}\text { Total number of } \\
\text { patients }\end{array}$ & $\begin{array}{l}1.99 \times 10^{6} \\
(90.4 \%)\end{array}$ & $\begin{array}{l}211120 \\
(9.6 \%)\end{array}$ & $\begin{array}{l}26550 \\
(12.6 \%)\end{array}$ & $\begin{array}{c}41812 \\
(19.8 \%)\end{array}$ & $\begin{array}{l}118388 \\
(56.1 \%)\end{array}$ & $\begin{array}{l}55237 \\
(26.2 \%)\end{array}$ & $\begin{array}{c}37495 \\
(17.8 \%)\end{array}$ \\
\hline $\begin{array}{l}\text { Age (years), median } \\
\text { (IQR) }\end{array}$ & $\begin{array}{c}65 \\
(44-78)\end{array}$ & $\begin{array}{c}67 \\
(53-76)\end{array}$ & $\begin{array}{c}68 \\
(60-75)\end{array}$ & $\begin{array}{c}68 \\
(56-76)\end{array}$ & $\begin{array}{c}67 \\
(54-76)\end{array}$ & $\begin{array}{c}66 \\
(52-77)\end{array}$ & $\begin{array}{c}66 \\
(52-77)\end{array}$ \\
\hline $\begin{array}{l}\text { Sex, male } \\
\text { Elective procedure } \\
\text { In-hospital death } \\
\text { LOS (days), median } \\
\text { (IQR) }\end{array}$ & $\begin{array}{c}986370 \\
(46.9 \%) \\
697134 \\
(31.7 \%) \\
28714 \\
(1.4 \%) \\
4 \\
(2-6)\end{array}$ & $\begin{array}{c}120563 \\
(57.1 \%) \\
90673 \\
(42.9 \%) \\
15407 \\
(7.3 \%) \\
7 \\
(4-13)\end{array}$ & $\begin{array}{c}19836 \\
(74.8 \%) \\
21163 \\
(79.7 \%) \\
511 \\
(1.9 \%) \\
10 \\
(8-14)\end{array}$ & $\begin{array}{c}22577 \\
(54.0 \%) \\
26875 \\
(64.3 \%) \\
2289 \\
(5.5 \%) \\
10 \\
(6-18)\end{array}$ & $\begin{array}{c}70763 \\
(59.8 \%) \\
64478 \\
(54.5 \%) \\
8670 \\
(7.3 \%) \\
9 \\
(5-15)\end{array}$ & $\begin{array}{c}29314 \\
(53.1 \%) \\
18251 \\
(33.0 \%) \\
4871 \\
(8.8 \%) \\
7 \\
(3-12)\end{array}$ & $\begin{array}{c}20486 \\
(54.6 \%) \\
7944 \\
(21.2 \%) \\
1866 \\
(5.0 \%) \\
4 \\
(2-8)\end{array}$ \\
\hline $\begin{array}{l}\text { HAC per } 100 \\
\text { separations, mean } \\
(95 \% \mathrm{CI})\end{array}$ & $\begin{array}{c}5.84 \\
(5.81-5.87)\end{array}$ & $\begin{array}{c}29.8 \\
(29.6-30.0)\end{array}$ & $\begin{array}{c}50.8 \\
(50.0-51.7)\end{array}$ & $\begin{array}{c}39.7 \\
(39.1-40.3)\end{array}$ & $\begin{array}{c}35.4 \\
(35.1-35.7)\end{array}$ & $\begin{array}{c}25.9 \\
(25.5-26.3)\end{array}$ & $\begin{array}{c}18.0 \\
(17.5-18.4)\end{array}$ \\
\hline $\begin{array}{l}\text { HAC per } 100 \text { bed- } \\
\text { days, mean }(95 \% \mathrm{Cl})\end{array}$ & $\begin{array}{c}1.31 \\
(1.30-1.32)\end{array}$ & $\begin{array}{c}4.79 \\
(4.76-4.82)\end{array}$ & $\begin{array}{c}6.32 \\
(6.23-6.40)\end{array}$ & $\begin{array}{c}4.88 \\
(4.82-4.93) \\
\end{array}$ & $\begin{array}{c}4.99 \\
(4.95-5.03)\end{array}$ & $\begin{array}{c}4.42 \\
(4.37-4.48) \\
\end{array}$ & $\begin{array}{c}4.41 \\
(4.33-4.45) \\
\end{array}$ \\
\hline
\end{tabular}

$I C U=$ intensive care unit; IQR = interquartile range; LOS = length of stay. * Major surgery refers to non-cardiac surgical admission to the ICU.

receiving any life-sustaining interventions (mean, $3.3[95 \%$ Cl, 3.2-3.3] per 100 bed-days). Rates for elective hospital admissions transferred to ICU were on average $11 \%(95 \% \mathrm{Cl}$, 10-12\%) higher than the corresponding rates for emergency (unplanned) hospital admissions transferred to ICU.

\section{Hospital variation}

Figure 2 presents the point estimate of the crude HAC event rates for multiday stay ward, ICU, and cardiac surgical separations in all 47 major hospitals within the State of Victoria. The rate for all subgroups was significantly higher in tertiary referral (mean, $35.4[95 \% \mathrm{Cl}, 35.1-35.7]$ per 100 ICU separations) than major metropolitan (mean, 25.9 [95\% Cl, 25.5-26.3] per $100 \mathrm{ICU}$ separations) or regional hospitals (mean, $18.0[95 \% \mathrm{Cl}, 17.5-18.4]$ per $100 \mathrm{ICU}$ separations).

Despite the apparent variation in crude HAC rates between hospital sites, the hospital level ICC for cardiac surgical (ICC, 0.03; 95\% Cl, 0.02-0.06), total ICU (ICC, $0.08 ; 95 \% \mathrm{Cl}, 0.05-0.11)$ and ward (ICC, $0.04 ; 95 \% \mathrm{Cl}$, $0.02-0.06)$ separations were all very low, suggesting that little of the observed variation in rates (Figure 2) was attributable to hospital factors.

In contrast, the margins plot (Figure 3 ) describes a significant relationship $(P<0.001)$ between the estimated risk of clinical deterioration and death (based solely on patient characteristics present at the time of admission to hospital) and the likelihood of a later HAC event during the same hospital episode. Data were limited to the financial year 2018-2019 $(n=467$ 008) and results dichotomised for ICU and ward separations.

\section{Discussion}

We analysed over 2 million consecutive (multiday stay) adult separations from all major (private and public sector) health services within the State of Victoria and identified that, on average, one in three ICU separations were reported to have experienced a HAC event, compared with one in 17 ward separations. Although ICU admission accounted for only $10 \%$ of hospital separations, these records were associated with $35 \%$ of all HAC events.

Unexpectedly higher rates of HAC events were reported in elective cardiac (one in two) and non-cardiac (one in three) post-surgical ICU admissions compared with emergency medical ICU admissions (one in four). Higher rates were also identified in tertiary hospitals (one in three ICU separations) than non-tertiary hospital ICUs (one in five ICU separations).

The mean rate of complications for general ward separations (5.8 per 100 separations or 1.3 per 100 beddays) was comparable to published rates, ${ }^{2,4,9}$ but our observed rate for ICU separations was substantially higher than previously reported (using a "gold standard" chart review method $\left.{ }^{17}\right)$ for ICU ${ }^{18-20}(10-19 \%)$, cardiac surgery 21 $(11 \%)$, emergency services ${ }^{22}(4 \%)$, and general medical ${ }^{23,24}$ $(6-8 \%)$ patient groups in which the majority were deemed unavoidable.

HAC events have several features consistent with health care-related errors: they are unwanted events arising in hospital, mitigated by preventive strategies, ${ }^{2}$ associated with adverse patient outcomes (death or prolonged stay ${ }^{4}$ ), and more common in some hospitals than others. ${ }^{25}$ Within this paradigm, high rates of HAC events are expected in 
Figure 2. Proportion of separations coded with hospital-acquired complications (HAC) events for each major hospital ward (grey circle), intensive care unit (ICU) (black circle) and cardiac surgical (open circle) subgroup, sorted by descending HAC rate for ICU separations. Dashed lines represent state average for each subgroup

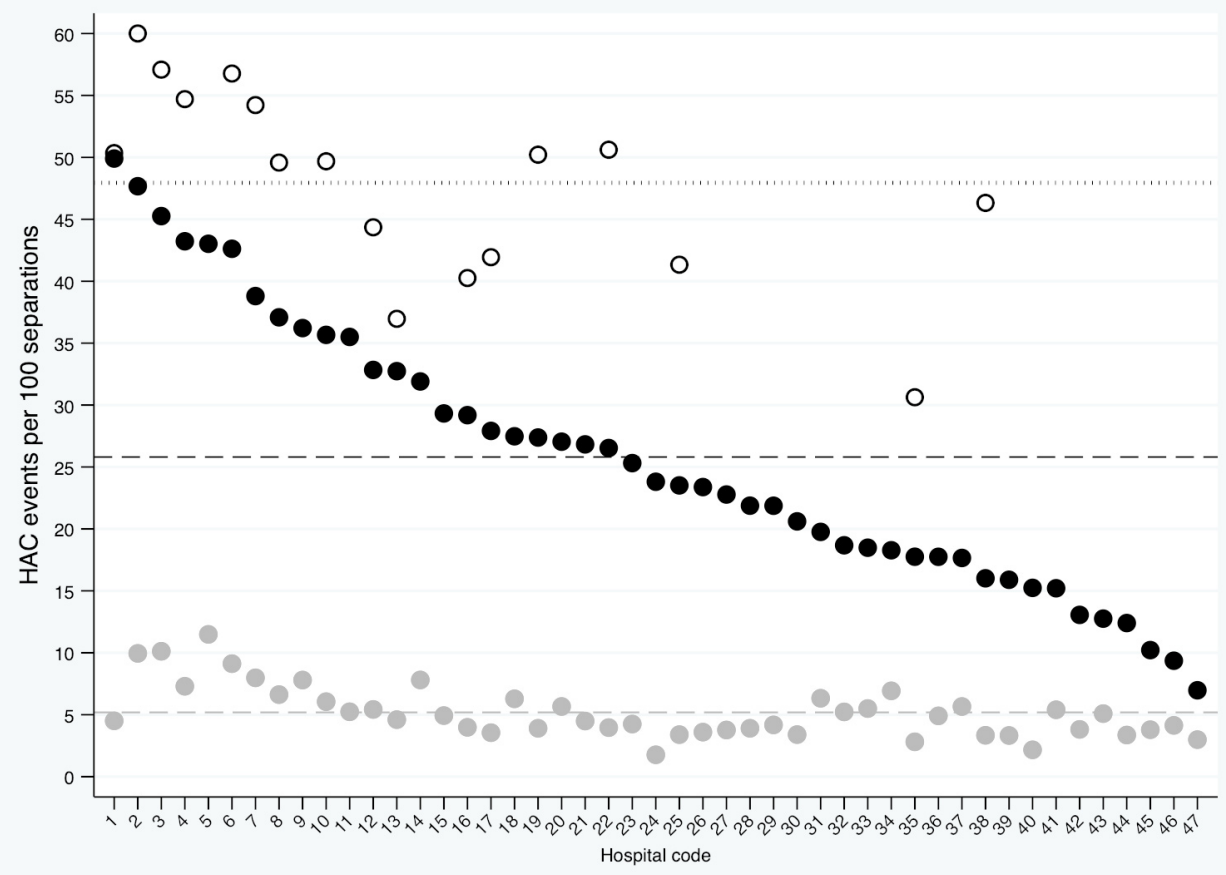

Figure 3. Margins plot $(95 \% \mathrm{Cl})$ of association between on-admission risk of clinical deterioration (mortality) and the risk of hospital-acquired complications (HAC) events during index admission for intensive care unit (ICU) (open circle) and ward (closed circle) separations

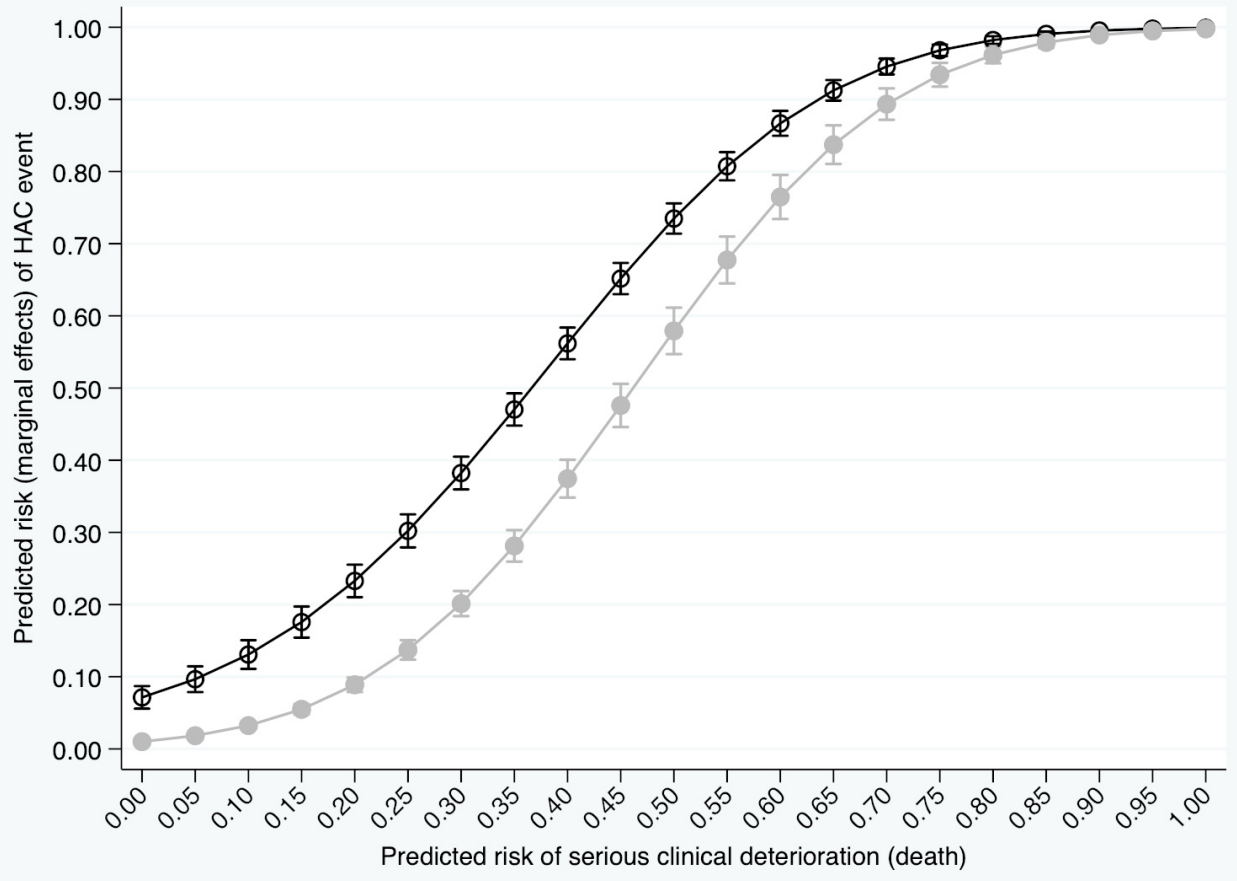

health services or wards providing a lower standard of care.

This interpretation of HAC rates is yet to be validated by clinical audit ${ }^{26}$ and does not explain the high rates seen in high volume and better resourced (tertiary) hospitals and ICU wards, which are expected to deliver a high standard of care and reduce health care errors. Nor does it explain the very high rates observed in stable patients undergoing elective surgical procedures compared with those requiring time-critical emergency medical treatment.

Alternatively, if the majority of HAC events are predictable patientrelated complications arising from disease and comorbidities (Table 1) during optimal care, ${ }^{25}$ then we are furnished with a plausible explanation for all the available evidence. It still fulfils the HAC definition ${ }^{1,9}$ yet is consistent with the strong association with pre-admission patient factors (Figure 3), the weak association (ICC) with hospital site, the higher frequency in tertiary hospitals and in ICU separations, and its association with increased health care costs (prolonged length of stay, ${ }^{4}$ higher mortality ${ }^{5}$. $\quad$ This perspective suggests 


\section{ORIGINAL ARTICLE}

that HAC events are an indicator of patient complexity; an indication of triage decisions based on the risk of clinical deterioration, rather than an indication of substandard care. $^{2}$

It should not be inferred from this interpretation that preventable health care errors do not occur and are not captured by the HAC methodology. ${ }^{25}$ The evidence only indicates they are not the principal or leading cause of HAC events. Each health service should review all records ${ }^{17,26}$ coded with HAC events to ensure that preventable hospitalrelated complication are identified and addressed. Given the high rate of HAC events in the ICU cohort, it is likely that intensivists will be called upon to interpret these data.

The common assumption, however, that HAC rates quantify a substantial volume of hospital-related complications is not supported by the evidence. ${ }^{18-24,26}$ Further refinement of the methodology, incorporating additional clinical data and robust risk-adjustment and clinical expertise, may result in a more reliable screening tool for preventable adverse events.

The strengths of this study include access to a large contemporary dataset, an easily replicated methodology, and the insight of experienced clinicians. However, it was limited by the extent of clinical details and the absence of chronological sequencing to determine aetiology. Further analysis in other jurisdictions and clinical audit of HAC events is warranted.

\section{Conclusions}

We analysed a contemporary dataset of over 200000 ICU separations and report a high rate of HAC events in critically ill adults. The common assumption that HAC measures hospital-related complications, where higher rates reflect a lower standard of care, remains unproven. The HAC methodology appears to be an indicator of patient complexity, where higher rates reflect the provision of care to sicker patients who are at high risk of clinical deterioration where lower rates are not necessarily reassuring.

\section{Competing interests}

No relevant disclosures.

\section{Author details}

Graeme J Duke1,2,3

Frank Shann $n^{3,4}$

Cameron I Knott ${ }^{3,5,6}$

Felix Oberender ${ }^{3,7}$

David V Pilcher $3,8,9$

Owen Roodenburg ${ }^{1,2}$

John D Santamaria3,10
1 Intensive Care Service, Eastern Health, Melbourne, VIC, Australia.

2 Faculty of Medicine, Nursing and Health Sciences, Monash University, Melbourne, VIC, Australia.

3 INSIGHT Committee, Critical Care Clinical Network, Safer Care Victoria, Melbourne, VIC, Australia.

4 Intensive Care Department, Royal Children's Hospital, Melbourne, VIC, Australia.

5 Intensive Care Department, Bendigo Health, Bendigo, VIC, Australia.

6 Intensive Care Department, Austin Health, Melbourne, VIC, Australia.

7 Paediatric Intensive Care Department, Monash Children's Hospital, Melbourne, VIC, Australia.

8 Intensive Care Department, Alfred Health, Melbourne, VIC, Australia.

9 Centre for Outcomes and Resource Evaluation, Australian and New Zealand Intensive Care Society, Melbourne, VIC, Australia.

10 Critical Care Department, St Vincent's Hospital Melbourne, Melbourne, VIC, Australia.

Correspondence: graeme.duke@easternhealth.org.au

doi: https://doi.org/10.51893/2021.3.OA5

\section{References}

1 Jackson TJ, Michel JL, Roberts RF, et al. A classification of hospital-acquired diagnoses for use with routine hospital data. Med J Aust 2009; 191: 544-8.

2 Australian Commission on Safety and Quality in Health Care. The state of patient safety and quality in Australian hospitals 2019. Sydney; ACSQHC, 2019. https://www.safetyandquality. gov.au/publications-and-resources/state-patient-safety-andquality-australian-hospitals-2019 (viewed Feb 2021).

3 Michel J, Nghiem HD, Jackson TJ. Using ICD-10-AM codes to characterise hospital-acquired complications. Health Inf Manag 2009; 38: 18-25.

4 Trentino KM, Swain SG, Burrows SA, et al. Measuring the incidence of hospital-acquired complications and their effect on length of stay using CHADx. Med J Aust 2013; 199: 543-7.

5 Aranaz-Andrés JM, Limón R, Mira JJ, et al. What makes hospitalized patients more vulnerable and increases their risk of experiencing an adverse event? Int J Qual Health Care 2011; 23: 705-12.

6 Department of Health and Human Services, Victoria State Government. Victorian Admitted Episode Dataset. https:// www2. health.vic.gov. au/hospitals-and-health-services/datareporting/health-data-standards-systems/data-collections/vaed (viewed Feb 2021).

7 Australian Institute of Health and Welfare. International Statistical Classification of Diseases and Related Health Problems, tenth revision, Australian Modification. https:// meteor.aihw.gov.au/content/index. phtml/itemld/391301 (viewed July 2021). 


\section{ORIGINAL ARTICLE}

8 National Centre for Classification in Health. Fundamentals of morbidity coding: using ICD-10-AM, ACHI and ACS, 10th ed. Sydney: University of Sydney, 2017.

9 Shepheard J, Lapiz E, Read C, Jackson TJ. Reconciling hospitalacquired complications and CHADx+ in Victorian coded hospital data. Health Inf Manag 2019; 48: 76-86.

10 van Walraven $C$, Austin PC, Jennings A, et al. A modification of the Elixhauser comorbidity measures into a point system for hospital death using administrative data. Medical Care 2009; 47: 626-33.

11 Gilbert T, Neuburger J, Kraindler J, et al. Development and validation of a Hospital Frailty Risk Score focusing on older people in acute care settings using electronic hospital records: an observational study. Lancet 2018; 391: 1775-82.

12 Australian Commission on Safety and Quality in Health Care. Hospital-acquired complications (HACs). https:// www.safetyandquality.gov.au/our-work/indicators/hospitalacquired-complications (viewed Feb 2021).

13 Heinze G, Dunkler D. Five myths about variable selection. Transpl Int 2017; 30: 6-10.

14 Kuha J. AIC and BIC: comparisons of assumptions and performance. Sociol Methods Res 2016; 33: 188-229.

15 Liljequist D, Elfving B, Skavberg Roaldsen K. Intraclass correlation: a discussion and demonstration of basic features. PLOS ONE 2019; 14: e0219854.

16 von Elm E, Altman DG, Egger $M$, et al. Strengthening the Reporting of Observational Studies in Epidemiology (STROBE) statement: guidelines for reporting observational studies. PLOS Med 2007; 4: e296.

17 Murff HJ, Patel VL, Hripcsak G, Bates DW. Detecting adverse events for patient safety research: a review of current methodologies. J Biomed Inform 2003; 36: 131-43.
18 Forster AJ, Kyeremanteng K, Hooper J, et al. The impact of adverse events in the intensive care unit on hospital mortality and length of stay. BMC Health Serv Res 2008; 8: 259-8.

19 McLaughlin N, Leslie GD, Williams TA, Dobb GJ. Examining the occurrence of adverse events within 72 hours of discharge from the intensive care unit. Anaes Intens Care 2007; 35: 486-93.

20 Forster AJ, Huang A, Lee TC, et al. Study of a multisite prospective adverse event surveillance system. BMJ Qual Saf 2020; 29: 277-85.

21 Brennan TA, Leape LL, Laird NM, et al. Incidence of adverse events and negligence in hospitalized patients. Results of the Harvard Medical Practice Study I. N Engl J Med 1991; 324: 370-6.

22 Wolff AM, Bourke J. Detecting and reducing adverse events in an Australian rural base hospital emergency department using medical record screening and review. Emerg Med J 2002; 19: 35-40.

23 Baines $R$, Langelaan $M$, de Bruijne $M$, et al. How effective are patient safety initiatives? A retrospective patient record review study of changes to patient safety over time. BMJ Qual Saf 2015; 24: 561-71.

24 Shojania KG, Marang-van de Mheen PJ. Temporal trends in patient safety in the Netherlands. BMJ Qual Saf 2015; 24: 541 4.

25 Victorian Agency for Health Information. Hospital-acquired complications in Victorian public health services 2020. https://www. bettersafercare.vic.gov.au/news-and-media/ new-hospital-acquired-complications-hacs-report-for-victoria (viewed Feb 2021).

26 Duke GJ, Loughan D, De Frietas M, et al. Clinical evaluation of the national hospital acquired complication program. Intern Med J 2021; doi: 10.1111/imj.15468 [Epub ahead of print]. 